\title{
Polymer functionalized gold nanoparticles as nonviral gene delivery reagents
}

\author{
M. Mar Encabo-Berzosa ${ }^{1,2+}$ (]) | Maria Sancho-Albero ${ }^{1,2 \dagger}$ | Victor Sebastian ${ }^{1,2}$ | \\ Silvia Irusta ${ }^{1,2}$ | Manuel Arruebo ${ }^{1,2}$ (1) | Jesus Santamaria ${ }^{1,2}$ | Pilar Martín Duque M,4 $^{3,4}$
}

\author{
${ }^{1}$ Department of Chemical Engineering. Aragon \\ Institute of Nanoscience (INA), University of \\ Zaragoza, Zaragoza, Spain \\ ${ }^{2}$ Networking Research Center on \\ Bioengineering, Biomaterials and \\ Nanomedicine, CIBER-BBN, Madrid, Spain \\ ${ }^{3}$ Facultad de Ciencias Biosanitarias, Carretera \\ Pozuelo a Majadahonda, Universidad \\ Francisco de Vitoria, Madrid, Spain \\ ${ }^{4}$ Fundación Araid, Zaragoza, Spain \\ Correspondence \\ Manuel Arruebo, Department of Chemical \\ Engineering. Aragon Institute of Nanoscience \\ (INA), University of Zaragoza, Campus Río \\ Ebro-Edificio I+D, C/Poeta Mariano Esquillor \\ S/N, 50018-Zaragoza, Spain. \\ Email: arruebom@unizar.es
}

Funding information

H2020 European Research Council, Grant/ Award Number: ERC-2013-CoG-614715

\begin{abstract}
Background: In the present study, we investigated the ability of polyethylene glycol (PEG) functionalized gold nanoparticles to function as nonviral vectors in the transfection of different cell lines, comparing them with commercial lipoplexes.

Methods: Positively-charged gold nanoparticles were synthesized using polyethylenimine (PEI) as a reducing and stabilizer agent and its cytotoxicity was reduced by its functionalization with PEG. We bound the nanoparticles to three plasmids with different sizes (4-40 kpb). Vector internalization was evaluated by confocal and electronic microscopy. Its transfection efficacy was studied by fluorescence microscopy and flow cytometry. The application of the resulting vector in gene therapy was evaluated indirectly using ganciclovir in HeLa cells transfected to express the herpes virus thymidine kinase.
\end{abstract}

Results: An appropriate ratio between the nitrogen from the PEl and the phosphorous from the phosphate groups of the DNA, together with a reduced size and an elevated electrokinetic potential, are responsible for an increased nanoparticle internalization and enhanced protein expression when carrying plasmids of up to $40 \mathrm{kbp}$ (plasmid size close to the limit of the DNA-carrying capacity of viral vectors). Compared to a commercial transfection reagent, an equal or even higher expression of reporter genes (on HeLa and Hek293t) and a suicide effect on HeLa cells transfected with the herpes virus thymidine kinase gene were observed when using this novel nanoparticulated vector.

Conclusions: Nonviral vectors based on gold nanoparticles covalently coupled with PEG and $\mathrm{PEI}$ can be used as efficient transfection reagents showing expression levels that are the same or greater than those obtained with commercially available lipoplexes.

\section{KEYWORDS}

gene therapy, nanobiotechnology, nanomedicine, transfection, vector polymeric

\section{1 | INTRODUCTION}

Nanoparticle-mediated transfection is characterized by a reduced immunogenicity and a low production cost, as well as an easy and scalable synthesis process compared to the highly efficient viral vectors (i.e. adenovirus, retrovirus, etc.). Endosomal escape, oligonucleotide protection and efficient condensation, and intracellular unpacking are the main drawbacks to overcome when designing nanoparticulated

${ }^{\dagger}$ M. Mar Encabo-Berzosa and Maria Sancho-Albero contributed equally to this work. transfection reagents. Not only nanoparticle diffusion, but also sedimentation influences cellular uptake, which represents a very important parameter to consider when carrying out in vitro studies. ${ }^{1}$ However, cellular uptake depends mainly on the oligonucleotide loading on the surface of the nanoparticulated carrier. ${ }^{2}$ Gilleron et al. ${ }^{3}$ demonstrated in vitro and in vivo that only a small fraction of the small interfering RNAs (siRNAs) was able to escape from the endosomes into the cytosol, when using lipid nanoparticles as short interfering siRNA delivery vectors. This gene delivery efficiency can be improved by promoting endosomal escape and by protecting the oligonucleotide from intra- and extracellular degradation. Drugs, peptides, lipids and cationic 
polymers have been added to nanoparticle-based formulations to promote this endosomal escape. ${ }^{4}$ The protection of the oligonucleotide of interest against enzymatic nuclease degradation can be carried out by encapsulation inside the nanoparticulated system ${ }^{5}$ or by means of layer-by-layer assembly of alternate polyelectrolytes on the surface of the nanoparticles together with the plasmid or siRNA. ${ }^{6}$ Finally, direct covalent coupling of the oligonucleotide to the nanoparticle reduces the susceptibility to nuclease degradation when the bond does not impair the oligonucleotide biological activity. ${ }^{7}$ Those benefits have supported several clinical trials using nanoparticles transporting plamids ${ }^{8}$ and siRNAs ${ }^{9}$ suppressing or silencing genes involved in cancer proliferation.

Rosi et al. ${ }^{7}$ demonstrated that, with the same amount of antisense oligonucleotide transported, gold nanoparticles can outperform the silencing efficiency in terms of protein percent knockdown compared to different commercially available transfection reagents with no signs of cytotoxicity at the doses tested. Lee et al. ${ }^{10}$ described the gene silencing efficiency of cysteamine modified gold nanoparticles decorated with polyethylenimine (PEI) and targeted using hyaluronic acid with luciferase-specific siRNA and vascular endothelial growth factor-specific siRNA in the presence of 50 vol \% serum to simulate in vivo conditions. Under those conditions, a 70\% reduction of the vascular endothelial growth factor mRNA level was measured for the nanoparticulated vector, whereas only a $20 \%$ reduction was observed for the commercial lipofectamine used as control. Simultaneous codelivery of siRNA and plasmidic DNA for knockdown and expression was demonstrated by Bishop et al. ${ }^{11}$ using polymer-coated (by layerby-layer) gold nanoparticles with a superior performance compared to commercially available transfection reagents at the same dosage in human brain cancer cells.

However, even with higher transfer efficiency, strategies designed to improve the oligonucleotide penetration and lower cytotoxicity are highly desirable. Accordingly, strategies using copolymers based on $\mathrm{PEI}$ and polyethylene glycol (PEG) and linked with cell penetrating peptides (i.e. trans-activating transcriptional activator TAT) have been widely used as transfection reagents. ${ }^{12}$ For those polyplexes, appropriate sizes (between 50 and $75 \mathrm{~nm}$ ) and PEI nitrogen to DNA phosphates ratios (30-40) are critical to achieving a high transfection efficiency. ${ }^{12}$ The use of PEI and PEG as transfection reagents has also been previously combined with magnetic nanoparticles. The conjugation of PEI to nanoparticles favors DNA sedimentation and cellular uptake and enhances the transfection efficiency. ${ }^{13}$ In this regard, Stephen et al. ${ }^{14}$ have recently reported the use of chitosan-PEG grafted with catechol functionalized with cationic PEI on the surface of magnetic nanoparticles. However, the transfection efficiency was reduced when PEG was used to reduce the cytotoxicity of the transfection reagent. In addition, PEG and PEI have also been grafted on the surface of carbon nanotubes $^{15}$ and graphene ${ }^{16}$ to silence target gene expression via RNA interference, taking advantage of the improved solubility provided by the PEG.

In general, PEG reduces nonspecific interactions with plasma proteins and nanoparticle-cell internalization with a consequent reduction in the transfection efficacy. Many PEG de-shielding strategies have been implemented to release the plasmid in vivo under the intracellular reductive conditions. ${ }^{17,18}$ Williams et al. ${ }^{19}$ demonstrated in vivo that neither the covalent coupling, nor the electrostatic interaction of gold nanoparticles to PEI/PEG increased the transfection efficiency and protein expression compared to the levels achieved with the PEI/PEG polyplexes alone. It was postulated that the electrostatic interaction was not sufficiently stable during the delivery and, for the case of the covalently grafted PEI/PEG, a low nanoparticle to PEI/PEG ratio might be responsible for such a reduced transfection efficiency.

In the present study, we describe a transfection reagent based on gold nanoparticles and PEG/PEI in which the transfection efficiency levels reached are equivalent or even superior under some conditions to commercially available transfection reagents using 3000,4700 and up to 40000 bp plasmids, with the later being close to the limit of the DNA-carrying capacity of viral vectors. ${ }^{20}$ Therefore, using those novel nanoparticles, not only electrostatic attraction, but also sedimentation ${ }^{21}$ can aid in moving the DNA to the cell wall.

\section{2 | MATERIALS AND METHODS}

\section{1 | Nanoparticle synthesis and characterization}

Au-PEI nanoparticles were synthesized using PEI branched (aproximately $25 \mathrm{kDa}$; Sigma-Aldrich, St Louis, MO, USA) as a reductant and stabilizer. Briefly, $1 \mathrm{~mL}$ of a $0.5 \times 10^{-3} \mathrm{M}$ PEI solution was added to $19 \mathrm{~mL}$ of a solution of $50 \mathrm{mg} \mathrm{L}^{-1}$ of $\mathrm{HAuCl}_{4}$ at room temperature under vigorous stirring. The resulting $\mathrm{Au}-\mathrm{PEI}$ nanoparticles were dialyzed (50 kDa cut-off) against distilled water to eliminate the unbounded PEl. Those nanoparticles were subsequently bound to PEG using an excess of monofunctional poly(ethylene glycol)methylether-thiol (800 Da MW; Sigma-Aldrich). Any excess of unbound PEG was removed by dialysis (14 kDa cut-off).

Preliminary electron microscopy observations were carried out in the Advanced Microscopy Laboratory of the Aragon Institute of Nanoscience, University of Zaragoza, using a T20-FEI microscope with a LaB6 electron source fitted with a 'SuperTwin ${ }^{\circledR}$ ' objective lens (FEI, Hillsboro, OR, USA), allowing a point-to-point resolution of $2.4 \AA$. Aberration corrected scanning transmission electron microscopy images were acquired using a high angle annular dark field detector in a FEI XFEG TITAN electron microscope (FEI, Hillsboro, OR, USA) operated at $300 \mathrm{kV}$ equipped with a CETCOR Cs-probe corrector (CEOS Company, Heidelberg, Germany) allowing formation of an electron probe of $0.08 \mathrm{~nm}$. The geometric aberrations of the probeforming system were controlled to allow a beam convergence of 24.7 mrad half angle to be elected. Phosphotungstic acid was used to visualize PEG and PEI functionalization. The zeta potential and the particlesize distribution were measured by dynamic light scattering (DLS) at pH 7 in a Brookhaven 90 Plus equipment using ZetaPals (Brookhaven Instruments Corp., Holtsville, NY, USA). Also, ultraviolet (UV)-visible spectroscopy (V670; Jasco, Easton, MD, USA) was used for the nanoparticle extinction spectrum evaluation. The bond between PEI, Au and PEG was studied by Fourier transform infrared spectroscopy. Nitrogen (from PEI) to phosphorous (from phosphate groups in the DNA) ratios were calculated using $X$-ray photoelectron spectroscopy (XPS) using an Axis Supra (Kratos Analytical, Manchester, UK). A monochromatic Al Ka X-ray radiation ( $\mathrm{hv}=1486.6 \mathrm{eV}$ ) was used as an excitation 
source at $15 \mathrm{kV}$ and $15 \mathrm{~mA}$. The peaks analysis was developed by CasaXPS (Casa Software Ltd, Teignmouth, UK). In this analysis, the core level P 2p3/2 centered at $133.4 \mathrm{eV}$ was attributed to the phosphate groups in the DNA in agreement with a previous study. ${ }^{22}$

\subsection{NPs/DNA complex formation and agarose gel electrophoresis retention assay}

Au-PEI and Au-PEI-PEG nanoparticles were complexed with DNA at different $\mu \mathrm{g} N P s \mu g^{-1}$ DNA weight $(w / w)$ ratios. The amount of DNA was kept constant $(1 \mu \mathrm{g})$ and the nanoparticle mass was varied from 10 to $50 \mu \mathrm{g}$ in a final volume of $50 \mu \mathrm{L}$. The complexes were incubated for $30 \mathrm{~min}$ at room temperature. The DNA binding ability of the NPs was evaluated using the agarose gel electrophoresis retention assay. The loading buffer was mixed with the complexes before adding them into $1 \%$ agarose gel containing SYBR Safe stain. After running the gel at $60 \mathrm{~V}$ for $40 \mathrm{~min}$, the migration of plasmidic DNA was visualized in a UV chamber (ChemiDoc RXS; Bio-Rad, Hercules, CA, USA). Moreover, the DNA/NPs binding ability was analyzed measuring the surface charge of the complexes by DLS in Brookhaven 90 Plus apparatus.

To study the DNA protection capacity of the nanoparticles, the Au-PEI or Au-PEI-PEG/DNA complexes were incubated with Notl and $\mathrm{Xhol}$ restriction enzymes for $1 \mathrm{~h}$ at $37^{\circ} \mathrm{C}$. The resulting digestion was added into a $1 \%$ agarose gel containing SYBR Safe stain and ran at $60 \mathrm{~V}$ for $40 \mathrm{~min}$. The migration of the fragment was visualized in a UV chamber (ChemiDoc RXS; Bio-Rad).

\section{3 | AFM analysis}

Atomic Force Microscope (AFM) measurements were made in liquid phase by the Quantitative Nanomechanical Measurement Peakforce intermittent contact technique, in a Multimode 8 (Bruker Co., Billerica, MA, USA). The applied force was $1 \mathrm{nN}$ and the tip used was a commercial tip (SNL model, type - C; Bruker) with a hardness around $0.5 \mathrm{~N} \mathrm{~m}^{-1}$.

\subsection{Cell culture and nanoparticle cytotoxicity evaluation}

HeLa and Hek293t cells were obtained from the Cancer Research UK Culture Collection (London, UK). Both types of cells were cultured in Dulbecco's modified Eagle's medium (DMEM) with $10 \%$ fetal bovine serum (Gibco, Gaithersburg, MD, USA), 1\% penicillin/streptomycin and $1 \%$ amphotericin and maintained at $37^{\circ} \mathrm{C}$ in a $5 \% \mathrm{CO}_{2}$-humidified incubator. For the cytotoxicity experiments, HeLa and Hek293t cells were seeded onto 96 multi-well plates at $5 \times 10^{3}$ or $1 \times 10^{4}$ cells per well, respectively. The toxicity of the different vectors (Au-PEI and Au-PEI-PEG nanoparticles) was evaluated using the AlamarBlue assay (Thermo Fisher, Waltham, MA, USA) after $24 \mathrm{~h}$ of incubation for different nanoparticle concentrations (12.5 $\mathrm{g} \mathrm{mL}^{-1}$ to $100 \mu \mathrm{gL}^{-1}$ ).

\section{5 | Confocal microscopy}

To assess the intracellular trafficking of the reporter gene pEGFP, confocal microscopy was used. The pEGFP was labeled with Laber IT ${ }^{8}$ MArray Cy5 (Mirus, Madison, WI, USA) in accordance with the manufacturer's instructions. For the DNA internalization assay, cells were cultured on sterile cover slips at $2 \times 10^{4}$ cells per dish before running confocal microscopy analysis. For that purpose, $1 \mu \mathrm{g}$ of labeledpEGFP was complexed with 20 or $30 \mu \mathrm{g}$ of Au-PEI-PEG nanoparticles or with $3 \mu \mathrm{L}$ of Lipofectamine 2000 in $50 \mu \mathrm{L}$ of DMEM. The complexes were incubated with cells for $4 \mathrm{~h}$. Afterwards, cells were washed with PBS twice and fixed with $4 \%$ para-formaldehyde for 20 min, followed by staining with phalloidin 488 to label the actin fibers and the cell nucleus with 4',6-diamidino-2-phenylindole. The intracellular localization of the resulting complexes inside the cells was confirmed using an Compact Type Oil FV10i confocal microscope (Olympus, Tokyo, Japan).

\section{6 | Transfection assays}

Three different plasmids were conjugated to Au-PEI-PEG nanoparticles: pEGFP, p $\triangle \mathrm{dTL}$ and pTK. pEGFP-N1 (Clontech, Palo Alto, CA, USA) is a $4.7 \mathrm{kbp}$ plasmid that encodes the green fluorescence protein under the cytomegalovirus promoter. The $\Delta \mathrm{dtL}$ was kindly provided by Dr. Ramón Alemany (Bellvitge Biomedical Research Institute, Barcelona, Spain). This $41.9 \mathrm{kbp}$ plasmid not only has the inactivated genome of an oncolytic virus, but also encodes a green fluorescence protein. ${ }^{23}$ pTK was provided by Dr. Jon Schoorlmmer (Fundación Araid, Zaragoza, Spain). This $5 \mathrm{kbp}$ expression vector encodes the herpes simplex virus thymidine kinase gene under the control of the thymidine kinase promoter. EGFP and $\Delta \mathrm{dtL}$ transfection efficiencies were evaluated by fluorescence microscopy, whereas EGFP expression was also quantified by flow cytometry. In addition, TK expression was indirectly measured studying the ganciclovir (GCV) cytotoxic effect in transfected cells because it is the prodrug that activates the suicide effect of TK. In all cases, the ratio between NPs and DNA was 20:1 and 30:1 w/w.

To carry out the fluorescence microscopy experiments, cells were seeded onto 96 multi-well plates at the densities noted above. Then, 125 or 250 ng of pEGFP or $\mathrm{p} \Delta \mathrm{dTL}$ was added to each well. First, the Au-PEI-PEG nanoparticles/DNA (20:1 and 30:1 w/w) or Lipofectamine/DNA complexes were incubated with HeLa or Hek293t cells for 24 or $48 \mathrm{~h}$. In the case of Lipofectamine, the culture medium was changed $4 \mathrm{~h}$ after its addition, and the Lipofectamine/DNA ratio was $3: 1(v / w)$, as normally indicated for our cell types. The green fluorescence was visualized using an IX81 inverted fluorescence microscope (Olympus). For the evaluation of the transfection efficiency using cytometry, cells were seeded onto six multi-well plates $\left(1 \times 10^{5}\right.$ cells per well). The transfection efficiency was evaluated by flow cytometry using a FACSAria separator cytometer (BD Biosciences, San Jose, CA, USA) under $488 \mathrm{~nm}$ laser excitation. Cells were incubated with $\mathrm{Au}$ PEI-PEG nanoparticles/DNA or Lipofectamine/DNA complexes for 24 or $48 \mathrm{~h}$. Also in this case, the medium of the cells treated with Lipofectamine was changed after $4 \mathrm{~h}$. At the desired time points, cells were harvested and EGFP expression quantified.

To follow-up the transfection effects with the plasmid encoding the thymidine kinase gene, cells were incubated with the complexes for $24 \mathrm{~h}$. Then, DMEM containing $1 \mathrm{mg} \mathrm{mL}^{-1}$ of GCV (Sigma-Aldrich) was added to the cellular cultures. GCV is a pro-drug that exerts antiproliferative effects in cells that express the thymidine kinase gene. Both types of cells (HeLa and Hek293t) were incubated with this GCV medium for $72 \mathrm{~h}$. Afterwards, an AlamarBlue assay was performed to analyze the cellular viability. 


\section{7 | Transmission electron microscopy}

To study the intracellular localization of Au-PEI and Au-PEI-PEG nanoparticles, HeLa cells were seeded at a $1 \times 10^{6}$ cell per plate density onto a $\mathrm{t} 75$ flask and cultured for $24 \mathrm{~h}$. At that time point, a dispersion of DMEM containing $10 \mu \mathrm{g} \mathrm{mL}^{-1}$ of Au-PEI or Au-PEI-PEG nanoparticles in a final volume of $10 \mathrm{~mL}$ was added to the culture. Cells were incubated with this dispersion for $24 \mathrm{~h}$. After that, cells were washed twice with PBS and trypsinized. The cellular pellet was fixed with $2.5 \%$ glutaraldehyde for $1 \mathrm{~h}$ and washed again twice with PBS. A post-fixation was performed for $1.5 \mathrm{~h}$ in $1 \%$ osmium tetroxide at room temperature. The samples were washed several times before their dehydration in graded series of ethanol $(30,50,70,95$ and $100 \mathrm{vol} \%)$ and propylene oxide. Both samples were then embedded in Durcupan (Sigma-Aldrich). Sections with a thickness of approximately $60 \mathrm{~nm}$ were mounted on nickel grids before their examination by a T20-FEl microscope and by a Titan Cube 60-300 TEM (FEI) operating in high angle annular dark field mode.

\section{8 | Statistical analysis}

Results are expressed as the mean $\pm \mathrm{SD}$. Statistical analysis was performed with STATA software (StataCorp, College Station, TX, USA). Student's $t$-test was used to assess statistical differences $(p<0.05)$ between groups with normal distribution and Kruskal-Wallis $(p<0.05)$ between groups with a non-normal distribution.

\section{3 | RESULTS}

\section{1 | Nanoparticle synthesis and characterization}

Figure 1 describes the morphology of the nanoparticulated gene carriers in the present study. DLS measurements revealed a hydrodynamic size distribution centered at $11.1 \pm 2 \mathrm{~nm}$ and histograms retrieved from the transmission electron microscopy (TEM) size
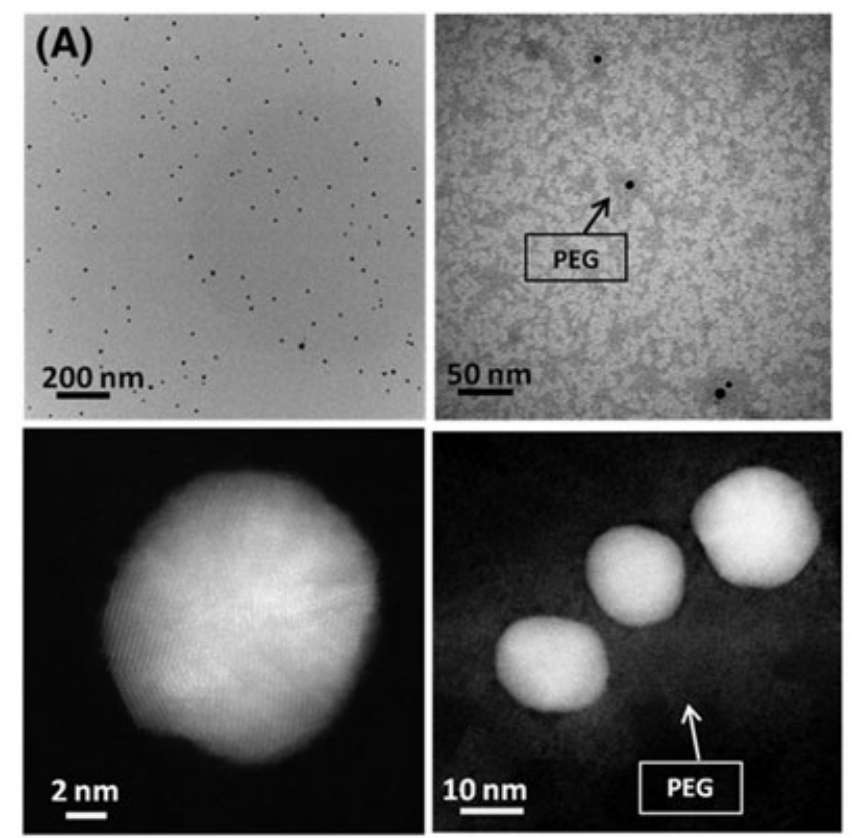

(B)

\begin{tabular}{lcc}
\hline & Size $(\mathbf{n m})$ & Z Potential $(\mathbf{m V})$ \\
Lipofectamine 2000 & 109,6 & $36,5 \pm 3,8$ \\
Lipo_pEGFP 1:3 & $516 \pm 45,9$ & $6,5 \pm 0,5$ \\
Au-PEI-pEGFP 20:1 & $87 \pm 2,2$ & $12,8 \pm 0,9$ \\
Au-PEI-pEGFP 30:1 & $101,9 \pm 4,8$ & $17,5 \pm 0,8$ \\
Au-PEI-PEG-pEGFP 20:1 & $125,7 \pm 8,8$ & $17,3 \pm 2,6$ \\
Au-PEI-PEG-pEGFP 30:1 & $123,3 \pm 3,3$ & $19,1 \pm 1$ \\
\hline
\end{tabular}

FIGURE 1 Au-PEI and Au-PEI-PEG nanoparticle characterization. (A) Au-PEI (left) and Au-PEG-PEI (right) nanoparticles TEM images (above) and STEM-HAADF image (bottom). The PEG corona is visible because of the phosphotungstic acid staining (right). (B) DLS analysis. Size of Lipofectamine and the nanoparticles incubated with pEGFP. Zeta potential of the Au-PEI-PEG nanoparticles after GFP plasmid coupling. The Z potential was measured at $\mathrm{pH} 7$ in distilled water. PEl-gold nanoparticles and PEG-PEI gold nanoparticles both without plasmids have a zeta potential of $+30.26 \pm 0.8 \mathrm{mV}$ and $+26 \pm 2.5 \mathrm{mV}$, respectively 
analysis on dried samples $(11,3 \pm 2 \mathrm{~nm})$ corroborated those sizes. The polycrystalline structure of the nanocrystals can be observed in the high-resolution transmission electron microscopy images. Also, an organic halo around the nanoparticles is indicative of the presence of the polymeric PEI and PEG corona. The colloidal Au-PEI-PEG nanoparticles in water show a maximum UV-visible extinction peak at around $520 \mathrm{~nm}$ (see Supporting information, Figure S1). This absorption is characteristic of the localized surface plasmon resonance peak of spherical gold nanocrystals as a result of the gold interband transitions reached when the value of the real part of the dielectric function of the particle material equals two times the dielectric constant of the solvent (water). ${ }^{24}$ The high extinction at low wavelengths observed is caused by the scattering of the samples. Zeta potential analysis revealed a positive charge for the colloidal Au-PEI-PEG nanoparticles, and an electrokinetic potential that was reduced after plasmid DNA (pEGFP) grafting but still positive to be able to electrostatically interact with the negatively charged cell surface glycoproteins. A reduced size (approximately five-fold less) and higher zeta potential (approximately three-fold more) was observed for the Au-PEI-PEG nanoparticles compared to Lipofectamine 2000 after DNA coupling.

Fourier transform infrared spectroscopy (FTIR) analysis (see Supporting information, Figure S1) was performed to evaluate the successful covalent coupling between the SH-PEG and the gold nanoparticles and also to corroborate the presence of the amino groups introduced by the PEI. SH-PEG exhibits the $\mathrm{S}-\mathrm{H}$ stretching vibrational mode appearing at around $2557 \mathrm{~cm}^{-1}$. As expected, subsequent to its reaction with $\mathrm{Au}-\mathrm{PEI}$ nanoparticles, the $\mathrm{S}-\mathrm{H}$ bond stretching vibrational band completely disappeared, which indicated the formation of the S-Au bond. ${ }^{25}$ This S-Au interaction is partially covalent (approximately $35 \%$ ) and mostly electrostatic (approximately $65 \%$ ). ${ }^{26} \mathrm{~N}-\mathrm{H}$ bending and $\mathrm{C}-\mathrm{N}$ stretching modes were observed near 1594 and $1120 \mathrm{~cm}^{-1}$, respectively. $\mathrm{CH}_{2}$ bending modes and $\mathrm{C}-\mathrm{C}$ stretching modes were also observed at 1454 and $1047 \mathrm{~cm}^{-1}$, respectively. Two $\mathrm{N}-\mathrm{H}$ stretching modes were detected for the primary amine group near 3355 and $3277 \mathrm{~cm}^{-1}$, and an overtone band near $3180 \mathrm{~cm}^{-1}$ was also present. The characteristic $\mathrm{C}-\mathrm{H}$ stretching modes were observed between 3000 and $2700 \mathrm{~cm}^{-1}$, with the most intense band being centered near $2805 \mathrm{~cm}^{-1}$. For Au-PEI nanoparticles, the relative intensity of the $\mathrm{C}-\mathrm{N}$ stretching mode was diminished relative to that of the $\mathrm{C}-\mathrm{C}$ stretching modes.

XPS analysis (see Supporting information, Table S1) also revealed the presence of phosphorus on the Au-PEI-PEG nanoparticles incubated with the DNA, revealing a N/P from phosphate ratio of 40.6 (see Supporting information, Table S1). This high ratio is a guarantee of a successful transfection in agreement with previous studies. ${ }^{12,13,27}$

\section{2 | DNA-nanoparticle complex formation and cytotoxicity evaluation}

The agarose gel electrophoresis assay demonstrated nanoparticle/ DNA electrostatic complexation (Figure 2). A constant amount of different plasmid DNA was complexed with Au-PEI or Au-PEI-PEG
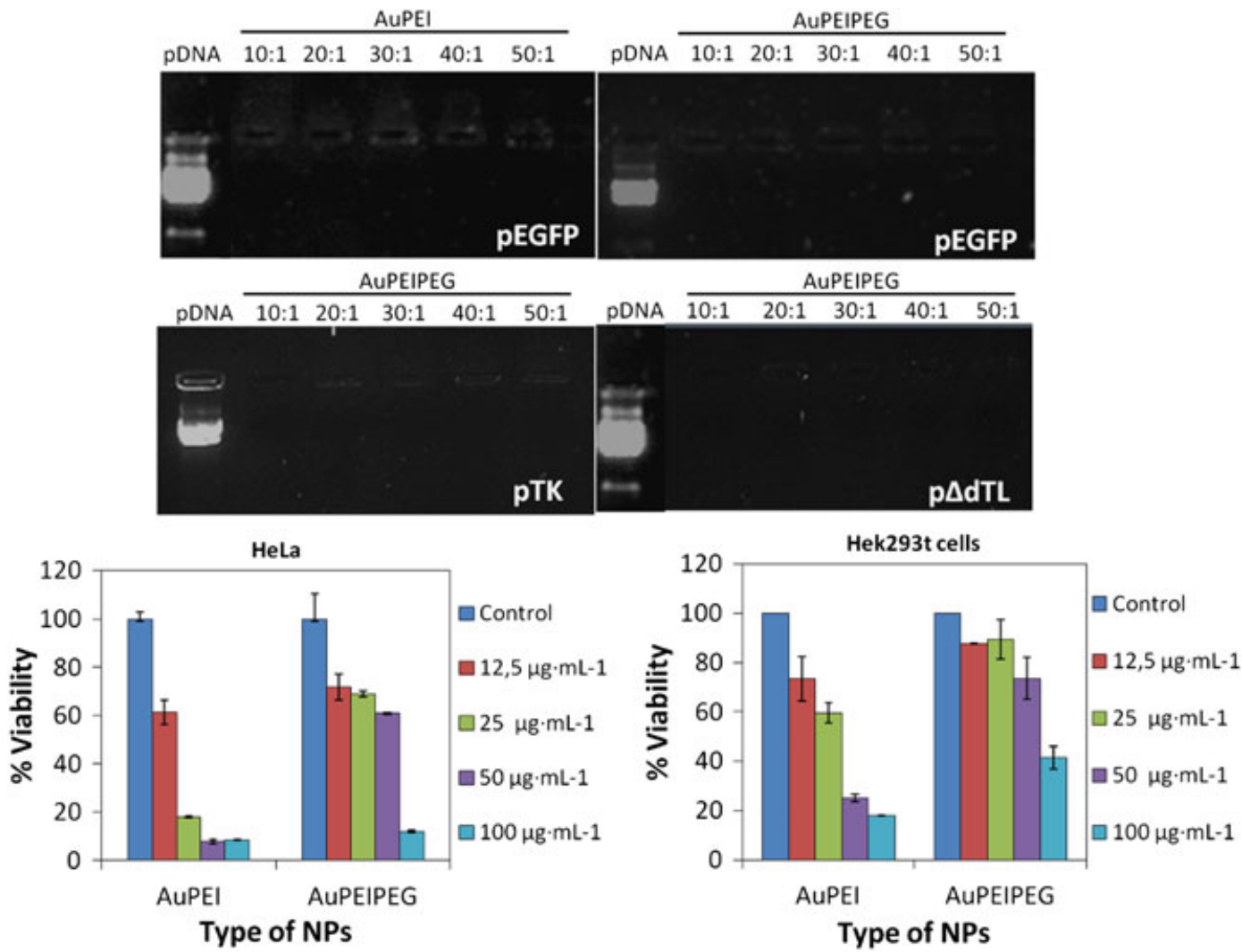

FIGURE 2 Biological characterization of Au-PEI and Au-PEI-PEG nanoparticles. Agarose gel electrophoresis for different Au-PEI and Au-PEI-PEG/ plasmid ratios $(w / w)$, the amount of DNA was kept constant and the amount of nanoparticles was increased from 10 to $50 \mu \mathrm{g}$ (above). Cytotoxicity evaluation of Au-PEI an Au-PEI-PEG nanoparticles in HeLa and Hek293t cells using the AlamarBlue assay (bottom). The toxicity was calculated relative to an untreated control for which $100 \%$ viability was set 
nanoparticles at different ratios of 50:1, 40:1, 30:1, 20:1 and 10:1 (nanoparticles:DNA). Maximum fluorescence signals were detected for the 20:1 and 30:1 samples, whereas, at higher nanoparticle loadings, the band was not clearly observed, probably caused by the fluorescence quenching by nanoparticle agglomeration in agreement with the previous literature ${ }^{27}$. To demonstrate the presence of the DNA, we use, as control, a 1:1 ratio of NPs:DNA (see Supporting information, Figure S2). In that large DNA excess, the genetic material was not totally bound to the NPs and a free DNA band was observed. Three different plasmids of different number of base pairs (3000, 4700 and up to $40000 \mathrm{kbp}$ ) were successfully complexed by the Au-PEI-PEG nanoparticles and no signs of plasmid fragmentation were observed.

Subcytotoxic doses for the Au-PEI and Au-PEI-PEG nanoparticles were investigated on different cell lines (HeLa and Hek293t), evaluating the resazurin colorimetric change in response to the cellular metabolism (Figure 2). Following the recommendations of the ISO 10993-5 in which viabilities higher than $70 \%$ are not considered cytotoxic, we proposed the in vitro use of Au-PEI-PEG nanoparticles at doses up to $50 \mu \mathrm{g} \mathrm{mL}^{-1}$ on Hek293t cells and up to $25 \mu \mathrm{g} \mathrm{mL} \mathrm{L}^{-1}$ on HeLa cells. Our results indicated that doses below $12.5 \mu \mathrm{g} \mathrm{mL}^{-1}$ could potentially be used for transfection applications on those cell lines when using just Au-PEI nanoparticles. Clearly, PEGylation reduced PEI cytotoxicity in agreement with the literature, ${ }^{28}$ probably caused by a reduced cell internalization.

We also analyzed the DNA protection from degradation using a gel retardation assay. Naked DNA showed degradation after treatment with the Xhol and Notl restriction enzymes (see Supporting information, Figure S3). By contrast, no significant loss of plasmid integrity was observed for the nanoparticulated complexes, indicative of a successful DNA condensation and protection in the polymeric nanoparticle corona. DNA condensation was also corroborated by AFM (see Supporting information, Figure S4) where a slight nanoparticle size increase was observed for the Au-PEI-PEG nanoparticles after DNA coupling and no free DNA was observed.

\section{3 | Transfection efficiency}

We observed how GFP expression was qualitatively enhanced when using both Au-PEI-PEG 20:1 and 30:1 (w/w) transfection reagents

\section{HeLa}
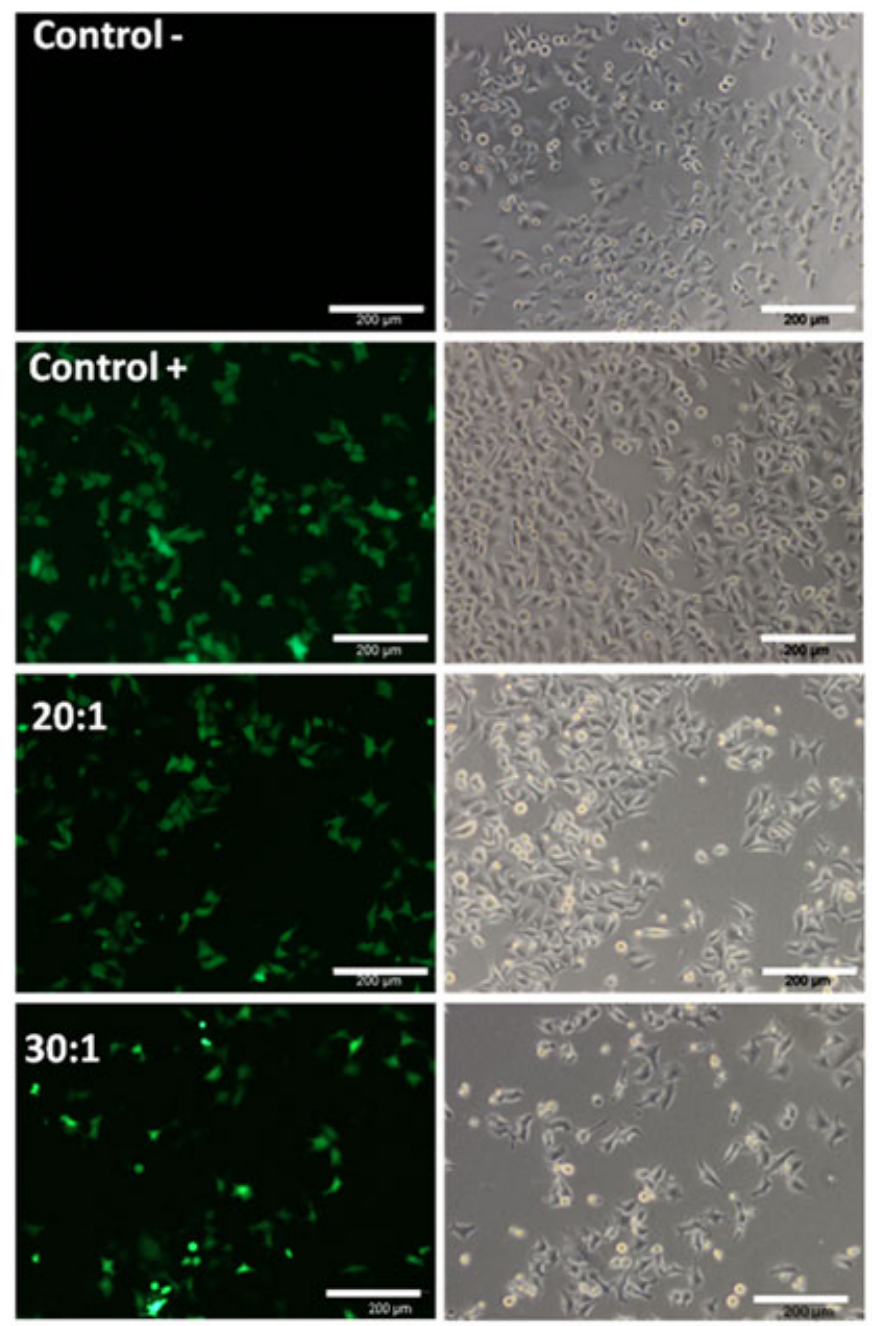

\section{Hek293t}
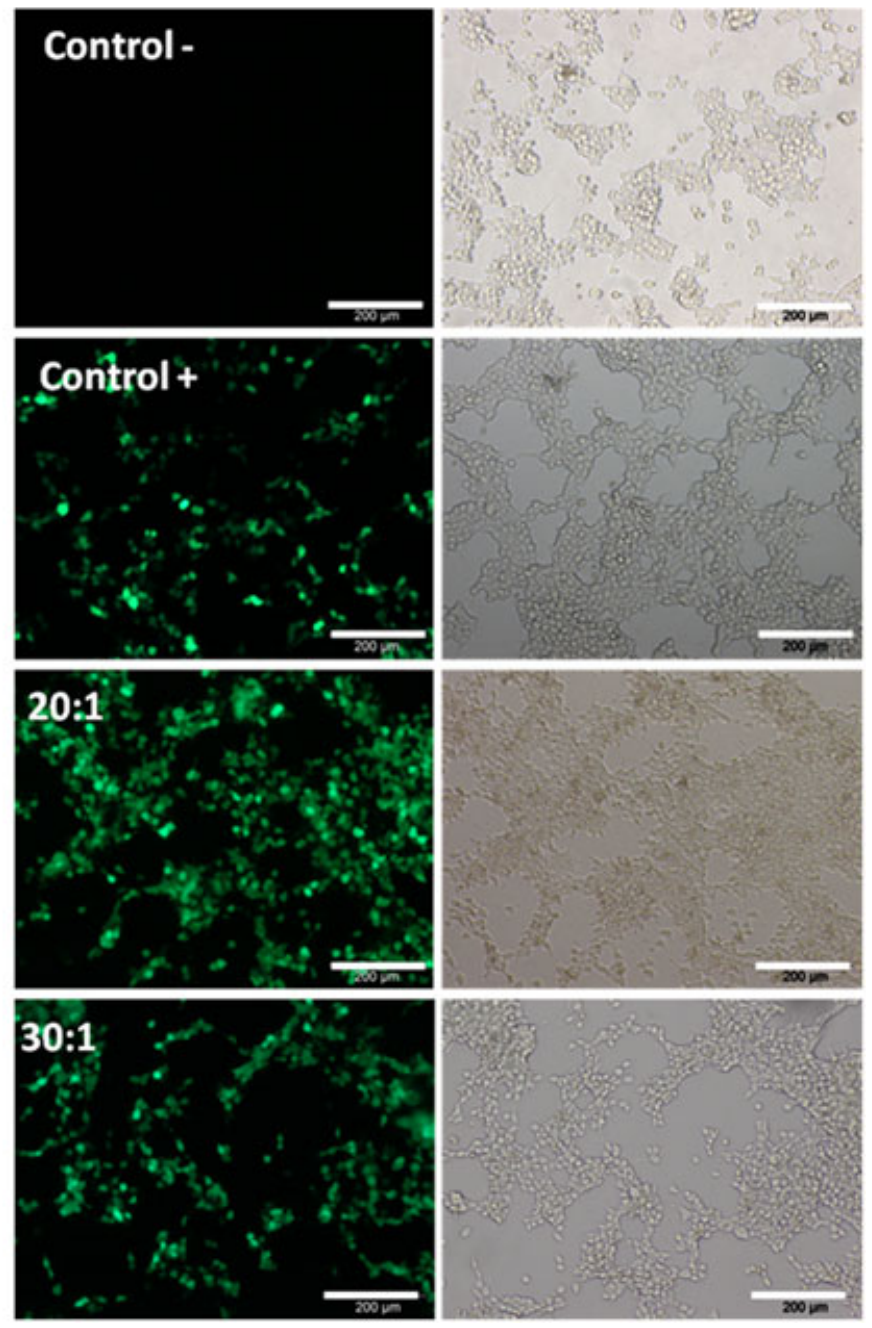

FIGURE 3 pEGFP transfection evaluation by fluorescence microscopy in HeLa and Hek293t cells. GFP fluorescence was evaluated at $488 / 520$ nm excitation/emission. All the images were acquired with the $\times 10$ objective $24 \mathrm{~h}$ after the addition of the complexes in a fluorescence inverted microscope IX81 (Olympus). Scale $=200 \mu \mathrm{m}$. Cells not incubated with any vector were used as negative control, whereas cells incubated with Lipofectamine/pEGFP complexes were used as a positive control 
compared to the commercial liposomal formulation (Figure 3) in both HeLa and Hek293t cell lines. Bright field images show that the morphology of the cell lines was not altered by the presence of the nanoparticles. HeLa cells remained elongated, growing adherently with epithelial morphology. Hek293t cells also remained unaltered, showing an epithelial adherent morphology.

Figure 4 shows the fluorescence quantification by flow cytometry from cells expressing the gene for green fluorescent protein (GFP) using the nanoparticles and the commercial Lipofectamine 2000. Similar results were obtained $24 \mathrm{~h}$ after transfection but, $48 \mathrm{~h}$ later, the green fluorescence intensity was higher $(p<0.05)$ when using AuPEI-PEG nanoparticles compared to the control. The percentage of GFP positive cells $48 \mathrm{~h}$ after the addition of the complexes was approximately a $15 \%$ higher for the $20: 1$ ratio than for the Lipofectamine-based control and, for the 30:1 ratio, the percentage of GFP positive cells $48 \mathrm{~h}$ after the addition of the complexes was a $20 \%$ higher than that obtained for the control.

A successful transfection was even achieved using the Au-PEIPEG nanoparticles as gene carriers of a 40000 bp plasmid (Figure 5).
Qualitatively, a higher transfection was achieved when using the gold-based nanocarriers. The transfection efficiency of large plasmids is limited by the slow transit through the intracellular vesicles by molecular crowding and small plasmids are usually diffusing faster towards the nuclei. ${ }^{29,30}$

Because one of the main purposes of this strategy would be the use of those NPs as vectors for gene therapy, we performed a classical approach of suicide gene therapy mediated by the herpes simplex virus thymidine kinase gene triggered by the prodrug ganciclovir. The gene product phosphorylates the nontoxic GCV into GCV triphosphate, which is incorporated into DNA in replicating cells, inhibiting DNA synthesis and resulting in cell death. ${ }^{31}$ Figure 6 shows the enhanced transgene efficient delivery when using the Au-PEI-PEG nanoparticles compared to the use of the commercial formulation.

Intracellular trafficking was monitored using Cy5 labeled-pEGFP complexed with either Au-PEI-PEG nanoparticles or with Lipofectamine 2000. As can be seen in Figure 7, after $4 \mathrm{~h}$ of incubation, complexes were visible in the cytoplasm of the HeLa cells. The presence of Lipofectamine/Cy5-DNA complexes in the extracellular matrix
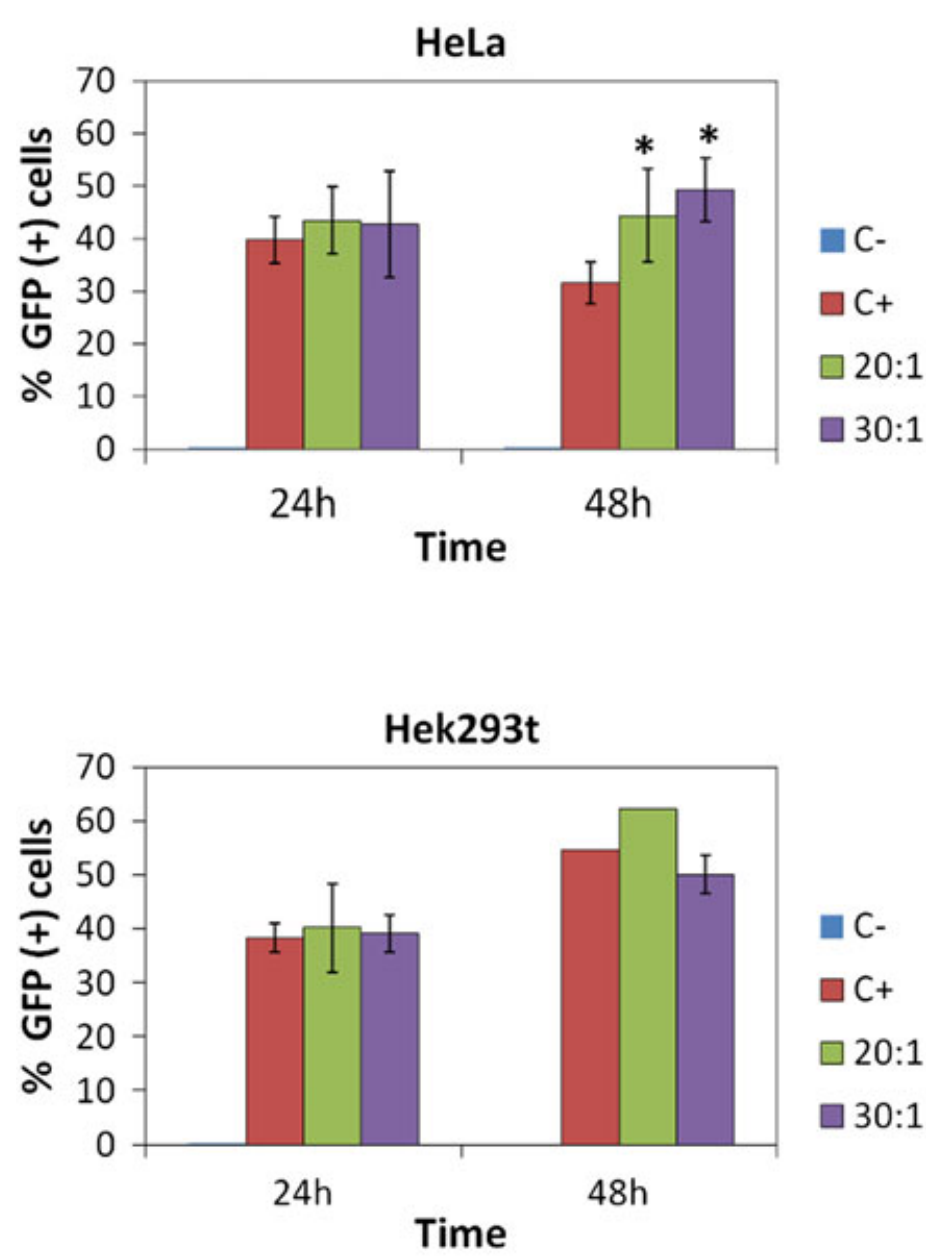
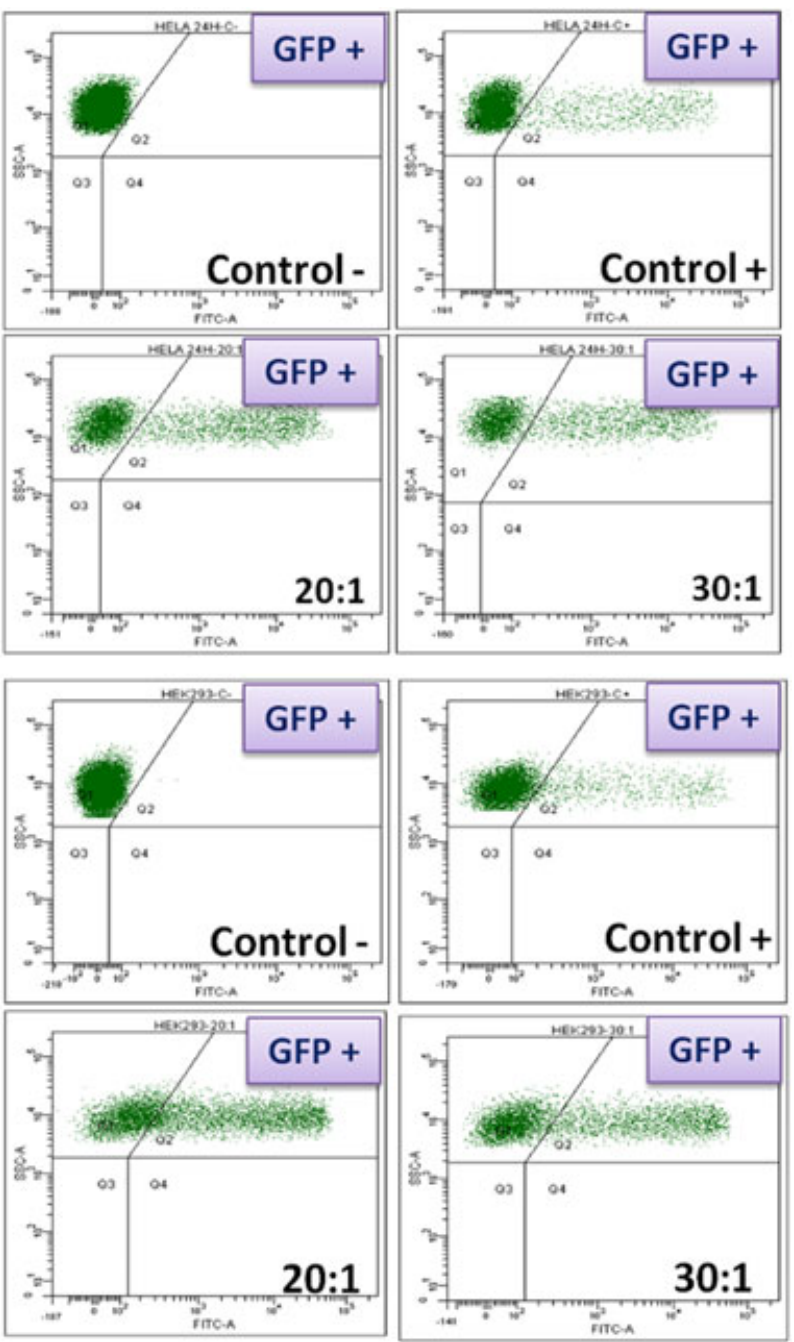

FIGURE 4 Fluorescence quantification by flow cytometry in HeLa and Hek293t cells. The cytometry graphs show the GFP positive cells at 48 h. Statistically significant differences are labelled with an asterisk $\left(^{*}\right)(p<0.05)$. Positive control represents the use of Lipofectamine 2000. Cells not incubated whit any vector were used as negative control 


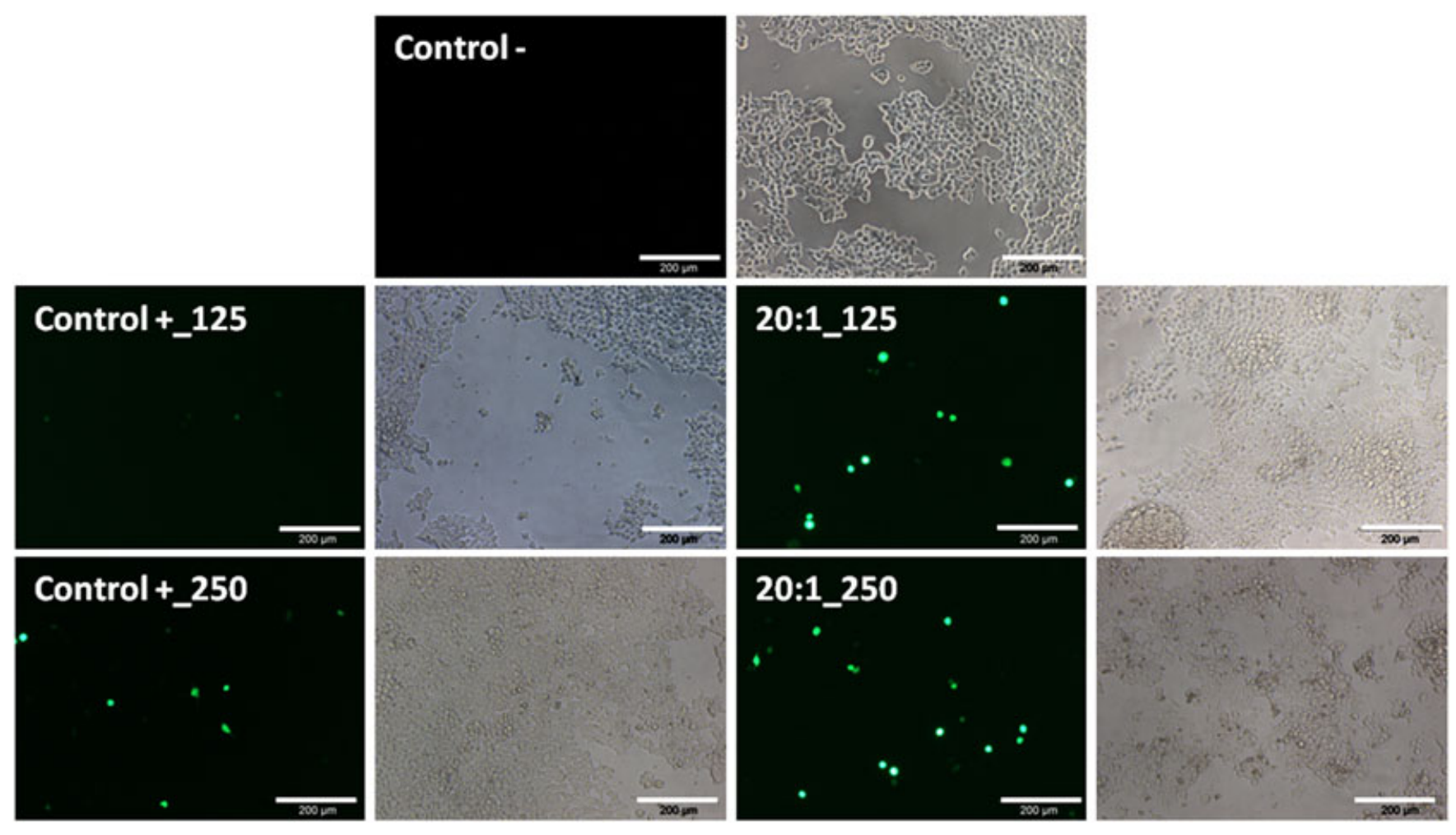

FIGURE $5 \mathrm{p} \triangle \mathrm{dTL}$ transfection evaluation by fluorescence microscopy on Hek293t cells. The images were taken in a fluorescence inverted microscope IX81 (Olympus). All the images were acquired with the $\times 10$ objective $24 \mathrm{~h}$ after the addition of the complexes. In these cases, two amounts of DNA were tested: 125 and $250 \mu \mathrm{g}$ per well. Cells not incubated with any vector were used as a negative control, whereas cells incubated with Lipofectamine $2000 / \mathrm{p} \Delta \mathrm{dTL}$ complexes were used as a positive control

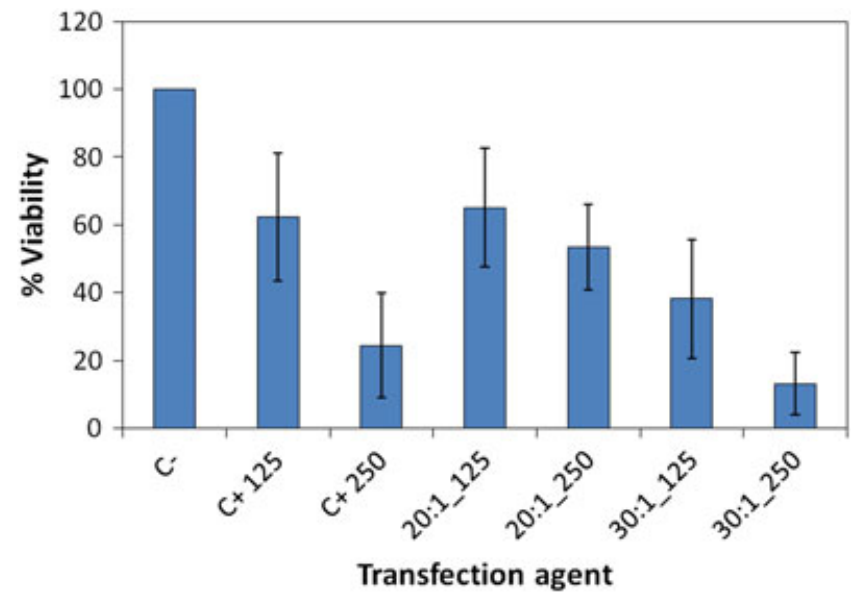

FIGURE 6 Cell viability using the thymidine kinase suicide gene under the presence of GCV in HeLa cells. Phosphorilated GCV is able to mediate the cell death at the doses studied. At the maximum nanoparticle concentration, the high presence of Au-PEI-PEG nanoparticles promote some death in the absence of GCV

clearly indicated the presence of larger agglomerates compared to those observed when using the nanoparticulated gene carriers. The orthogonal projections of the confocal images clearly show that some labeled plasmids are located inside of the nuclei of the cells. The internalization of types of nanoparticles was also evaluated by high-resolution transmission electron microscopy in HeLa cells. Figure 8 shows the intracellular distribution of both types of nanoparticles inside the cell cytosol. After $24 \mathrm{~h}$ of incubation, the nanoparticles were accumulated forming aggregates within intracellular vesicles without reaching the cellular nucleus.

\section{4 | DISCUSSION}

The transfection efficiency of nanoparticulated carriers can be improved when combining an adequate electrokinetic potential, which is able to electrostatically bind condensed DNA, with appropriate gene-vector dispersion and reduced agglomeration in the culture media. PEI provides the surface charge needed for a successful transfection as a result of its large buffering and endosomolytic ability and PEG provides reduced unspecific adsorption and steric hindrance. However, this PEI buffering ability and consequent change in the endosomal $\mathrm{pH}$ is still a matter of debate $\mathrm{e}^{32}$ and, most likely, its degradative action on the $\mathrm{pH}$-dependent endosomal compartment is responsible for the DNA release. Despite the successful transfection efficiency of $\mathrm{PEI}$, this cationic macromolecule acts as an apoptotic agent disrupting the plasma membrane and altering the mitochondrial membrane. ${ }^{33}$ As noted above, PEG has been introduced in PEI-based vectors to improve their solubility and to reduce their cytotoxicity but with the main drawback of reducing the efficiency compared to that achieved with the non-PEGylated vector. The reduction in the cytotoxicity induced by the PEG is a result of its mitigation ability with respect to the charge-induced toxicity. ${ }^{14}$ This charge reduction decreases the PEI buffering ability and also the successive washing steps that follow to anchor PEG on the PEI-based vector and 

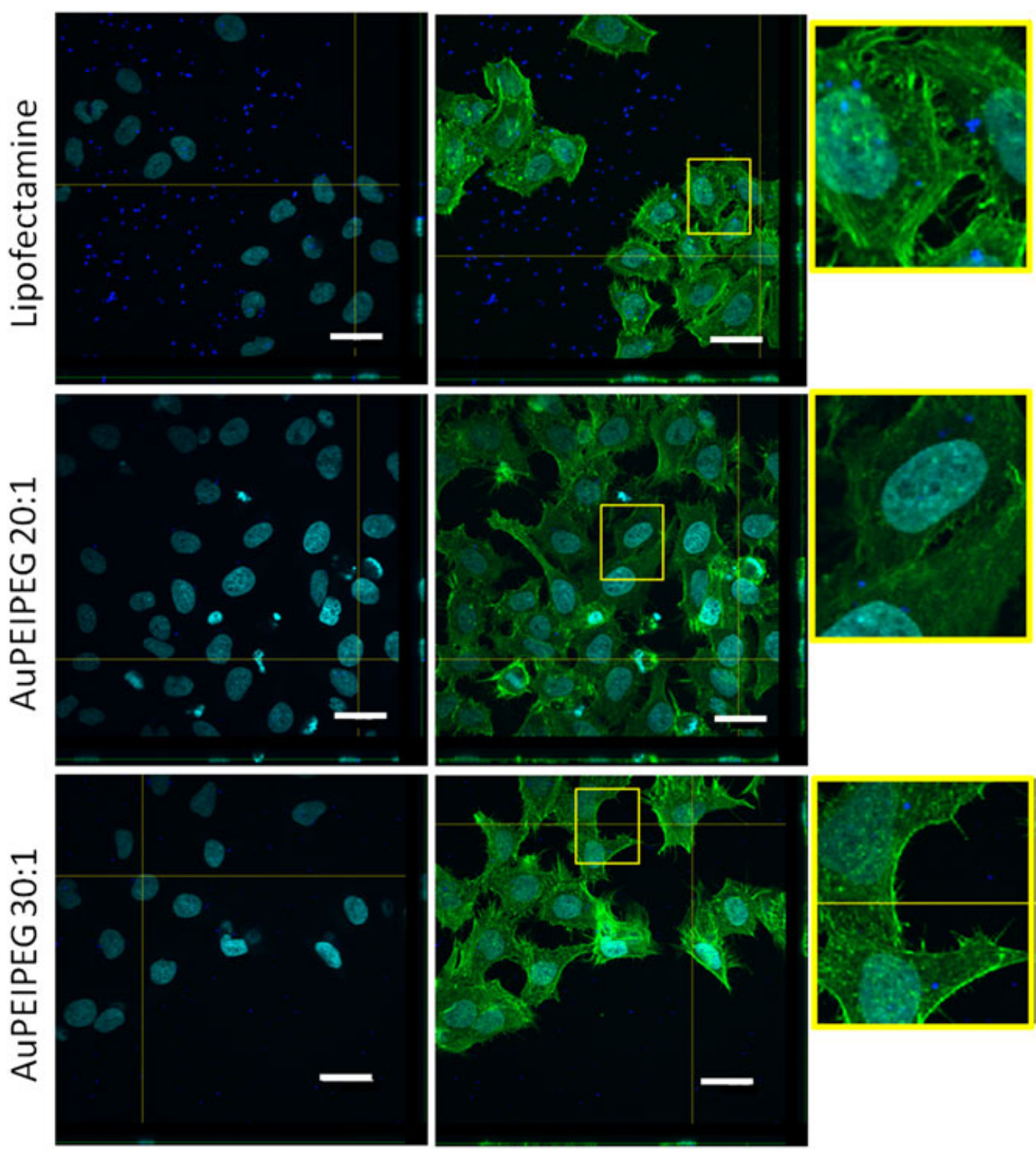

FIGURE 7 Internalization complexes evaluation by confocal microscopy. Intracellular trafficking of fluorescently (Cy5) labeled GFP plasmid bound to either Lipofectamine or Au-PEI-PEG nanoparticles after $4 \mathrm{~h}$ of incubation. HeLa cells were fixed and visualized by confocal microscopy. Actin fibers are shown in green and nuclei in cyan. The labelled plasmid DNA is shown in blue. Scale $=200 \mu \mathrm{m}$

participate in removing unbound PEI, which contributes to an efficient gene expression. ${ }^{34}$ We clearly demonstrate (Figure 3).that PEG reduces the $\mathrm{PEI}$ cytotoxicity probably caused by a reduction in the negative charge considering that the electrokinetic potential of $\mathrm{Au}$ PEl in water was $+30.4 \pm 0.8 \mathrm{mV}$ and, after PEG grafting, the Au-PEIPEG nanoparticles showed a zeta potential of $+26.2 \pm 2.4 \mathrm{mV}$ (Figure 1). Enzymatic degradation is not responsible for a successful gene transfer carried out by the nanoparticulated systems. We observed that no significant loss of plasmid integrity was observed after treating the nanoconjugated plasmids with restriction enzymes. This is an indication that just PEI is a successful reagent to condense plasmid DNA and protect it from degradation in the cytosol by achieving a more stable form with longer retention times than free DNA. ${ }^{35}$ It has been postulated that PEI offers a steric and/or electrostatic barrier to the diffusion of the restriction enzyme towards the protected DNA. ${ }^{36}$ The different transfection levels achieved for the two cell lines tested might be attributed to the different cell-specific intracellular barriers for the plasmid to overcome, as well as to the different transcription efficiencies and consequent protein expression. It has been reported that Hek293t cells exhibit the highest level of PEI-mediated GFP transfection, with $50-80 \%$ of cells showing protein expression. ${ }^{37}$ The gene expression levels obtained on HeLa cells were lower than those obtained with Hek293t cells (Figures 3 and 4), which can be attributed to the higher cytotoxicity of the Au-PEI-PEG nanoparticles on the HeLa cells at the same doses (Figure 3). In addition, the $293 \mathrm{t}$ cell line contains the SV40 Large T-antigen, which allows for episomal replication of transfected plasmids containing SV40, as for the pEGFP used in the present study. ${ }^{29}$ For that reason, the amplification product might have a larger temporal expression in the Hek293t cell line.

Lukacs et al. ${ }^{38}$ demonstrated that plasmid DNA with sizes above $250 \mathrm{bp}$ remains almost immobile in the cytoplasm because of molecular crowding; however, PEI has demonstrated efficient transfection of 

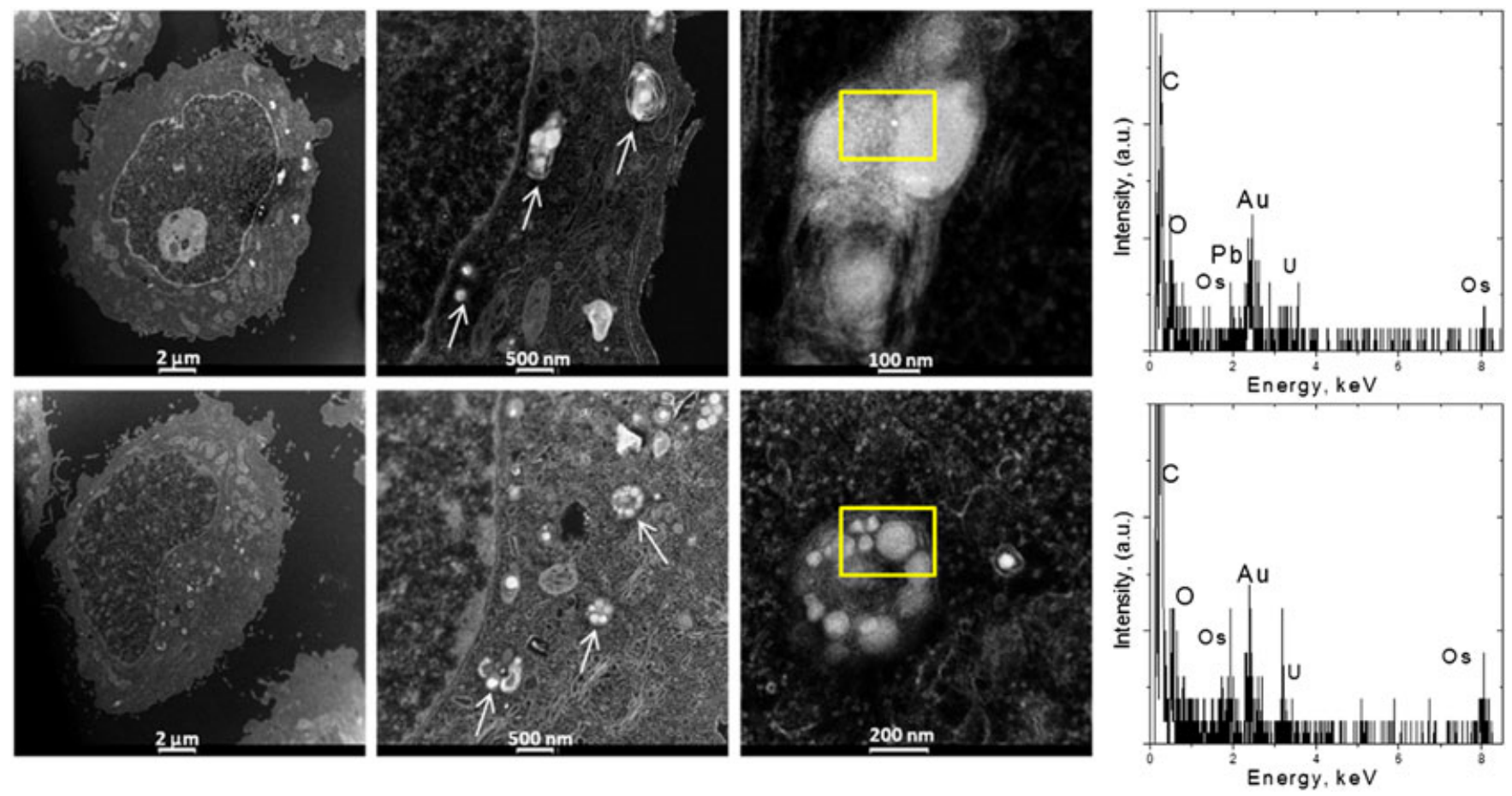

FIGURE 8 Internalization nanoparticle evaluation by TEM. Intracellular internalization of Au-PEI (above) and Au-PEI-PEG (bottom) nanoparticles evaluated in high angle annular dark field mode. HeLa cells were incubated with Au-PEI (above) or Au-PEI-PEG (bottom) for 24 h, the arrows indicate the presence of the nanoparticles and their intracellular presence within vesicles. The presence of gold was confirmed in both cases by energy-dispersive $\mathrm{X}$-ray analysis

large plasmids, being able to unpack and release the DNA, which then diffuses to the nuclei. Large plasmid DNA (52.5 kbp) resulted in an unsuccessful transfection efficiency when using lipoplexes because of the incipient colloidal instability related to the size and morphology of the polyplex invariant, irrespective of the plasmid size. ${ }^{30}$ Viral vectors have been used linked to PEI to enhance transfection efficiency when using 'large' plasmids. In this regard, 12-kpb plasmids have been linked to PEI and to an adenovirus for a successful transfection of human primary myoblasts. ${ }^{39}$ In the present study, we demonstrated how, qualitatively, a superior gene expression was achieved when using Au-PEI-PEG nanoparticles compared to the use of the commercial lipoplexe carrying a $40 \mathrm{kbp}$ plasmid. This efficiency difference might be attributed to the PEG ability in retarding endosomal escape, as reported previously. ${ }^{40}$

Particle size affects gene expression and a reduced gene vector agglomeration in the culture media favors DNA internalization. Large agglomerates sediment and interact easily with the cellular membrane; however, larger agglomerates are excluded from the endocytic route and are usually internalized following macropinocytosis in which the internalized cargo is stored in the lysosomal compartment. ${ }^{41}$ Therefore, we propose that the lack of large agglomerates with sizes above $200 \mathrm{~nm}$ (which is the optical resolution of the confocal microscope used) are responsible for a successful transfection efficiency for our Au-PEI-PEG nanocarriers compared to the Lipofectamine 2000 reagent where clear plasmid agglomerates were observed in the culture media (Figure 7).

Compared to the commercial transfection reagent, the reduced cytotoxicity of Au-PEI-PEG nanoparticles, together with their sedimentation ability on the culture cells and their reduced size, are responsible for the high levels of transgene expression observed. In addition, gold might potentially provide a dual function, being not only a gene carrier, but also a well known contrast agent in different medical imaging technologies, including optical coherence tomography, ${ }^{42}$ computed tomography, ${ }^{43}$ photoacoustic tomography, ${ }^{44}$ etc.

\section{5 | CONCLUSIONS}

Gold nanoparticles can be employed as nonviral vectors for gene expression using PEI as a surface functional agent. PEI condensates and protects the carried plasmid from enzymatic degradation. The PEGylation of those nanoparticles by covalent coupling reduces the PEI cytotoxicity, and also enhances nanoparticle dispersion in culture media. Different plasmids with a different number of pair bases can be transfected using this vector and plasmids of up to $40 \mathrm{kpb}$ can be transfected with a superior performance compared to that obtained with commercially available lipoplexes. Not only reporter genes, but also a superior suicide effect in cells transfected with the herpes virus thymidine kinase gene mediated by ganciclovir was observed using the nanoparticulated vector.

\section{ACKNOWLEDGEMENTS}

The financial support of the EU (H2020 European Research Council) in relation to the ERC Consolidator Grant program (ERC-2013-CoG614715, NANOHEDONISM) is gratefully acknowledged. CIBER-BBN is an initiative funded by the VI National R\&D\&i Plan 2008-2011, Iniciativa Ingenio 2010, Consolider Program, CIBER Actions and 
financed by the Instituto de Salud Carlos III (Spain) with assistance from the European Regional Development Fund. The authors declare that they have no conflicts of interest.

\section{REFERENCES}

1. Cho EC, Zhang Q, Xia Y. The effect of sedimentation and diffusion on cellular uptake of gold nanoparticles. Nat Nanotechnol. 2011;6:385-391.

2. Giljohann DA, Seferos DS, Patel PC, Millstone JE, Rosi NL, Mirkin CA. Oligonucleotide loading determines cellular uptake of DNA-modified gold nanoparticles. Nano Lett. 2007;7:3818-3821.

3. Gilleron J, Querbes W, Zeigerer A, et al. Image-based analysis of lipid nanoparticle-mediated siRNA delivery, intracellular trafficking and endosomal escape. Nat Biotechnol. 2013;31:638-646.

4. Cheng CJ, Tietjen GT, Saucier-Sawyer JK, Saltzman WM. A holistic approach to targeting disease with polymeric nanoparticles. Nat Rev Drug Discov. 2015;14:239-247.

5. Danhier F, Ansorena E, Silva JM, Coco R, Le Breton A, Préat V. PLGAbased nanoparticles: An overview of biomedical applications. J Control Release. 2012;161:505-522.

6. Han L, Zhao J, Zhang X, et al. Enhanced siRNA delivery and silencing gold-chitosan nanosystem with surface charge-reversal polymer assembly and good biocompatibility. ACS Nano. 2012;6:7340-7351.

7. Rosi NL, Giljohann DA, Thaxton CS, Lytton-Jean AKR, Han MS, Mirkin CA. Oligonucleotide-modified gold nanoparticles for intracellular Gene regulation. Science. 2006;312:1027-1030.

8. Senzer N, Nemunaitis J, Nemunaitis D, et al. Phase I study of a systemically delivered $\mathrm{p} 53$ nanoparticle in advanced solid tumors. Mol Ther. 2013;21:1096-1103.

9. Tabernero J, Shapiro GI, LoRusso PM, et al. First-in-humans trial of an RNA interference therapeutic targeting VEGF and KSP in cancer patients with liver involvement. Cancer Discov. 2013;3:406-417.

10. Lee MY, Park SJ, Park K, Kim KS, Lee H, Hahn SK. Target-specific gene silencing of layer-by-layer assembled gold-cysteamine/siRNA/PEI/HA nanocomplex. ACS Nano. 2011;5:6138-6147.

11. Bishop CJ, Tzeng SY, Green JJ. Degradable polymer-coated gold nanoparticles for co-delivery of DNA and siRNA. Acta Biomater. 2015;11:393-403.

12. Ulasov AV, Khramtsov YV, Trusov GA, Rosenkranz AA, Sverdlov ED, Sobolev AS. Properties of PEI-based polyplex nanoparticles that correlate with their transfection efficacy. Mol Ther. 2011;19:103-112.

13. Thomas M, Klibanov AM. Conjugation to gold nanoparticles enhances polyethylenimine's transfer of plasmid DNA into mammalian cells. Proc Natl Acad Sci U S A. 2003;100:9138-9143.

14. Stephen Z, Dayringer C, Lim J, et al. Approach to Rapid Synthesis and Functionalization of Iron Oxide Nanoparticles for High Gene Transfection. ACS Appl Mater Interfaces. 2016;8:6320-6328.

15. Taghavi S, HashemNia A, Mosaffa F, Askarian S, Abnous K, Ramezani M. Preparation and evaluation of polyethylenimine-functionalized carbon nanotubes tagged with 5TR1 aptamer for targeted delivery of Bcl-xL shRNA into breast cancer cells. Colloids Surfaces B Biointerfaces. 2016;140:28-39.

16. Wang C, Wang X, Lu T, et al. Multi-functionalized graphene oxide complex as a plasmid delivery system for targeting hepatocellular carcinoma therapy. RSC Adv. 2016;6:22461-22468.

17. Zhu H, Dong C, Dong H, et al. Cleavable PEGylation and hydrophobic histidylation of polylysine for siRNA delivery and tumor gene therapy. ACS Appl Mater Interfaces. 2014;6:10393-10407.

18. Noga M, Edinger D, Kläger R, et al. The effect of molar mass and degree of hydroxyethylation on the controlled shielding and deshielding of hydroxyethyl starch-coated polyplexes. Biomaterials. 2013;34:2530-2538
19. Williams JH, Schray RC, Sirsi SR, Lutz GJ. Nanopolymers improve delivery of exon skipping oligonucleotides and concomitant dystrophin expression in skeletal muscle of mdx mice. BMC Biotechnol. 2008;8:35

20. Friedmann T. Overcoming the obstacles to gene therapy. Sci Am. 1997;96-101.

21. Cho EC, Zhang Q, Xia Y. The effect of sedimentation and diffusion on cellular uptake of gold nanoparticles. Nat Nano. 2011;6:385-391.

22. Gomes PJ, Ferraria AM, Botelho Do Rego AM, Hoffmann SV, Ribeiro PA, Raposo M. Energy thresholds of DNA damage induced by UV radiation: An XPS study. J Phys Chem B. 2015;119:5404-5411.

23. Alemany R, Curiel DT. CAR-binding ablation does not change biodistribution and toxicity of adenoviral vectors. Gene Ther. 2001;8:1347-1353.

24. Rodríguez-González B, Sánchez-Iglesias A, Giersig M, Liz-Marzán LM. AuAg bimetallic nanoparticles: Formation, silica-coating and selective etching. Faraday Discuss. 2004;125:133-144.

25. Álvarez-Puebla RA, Contreras-Cáceres R, Pastoriza-Santos I, PérezJuste J, Liz-Marzán LM. Au@pNIPAM colloids as molecular traps for surface-enhanced, spectroscopic, ultra-sensitive analysis. Angew Chemie - Int Ed. 2009;48:138-143.

26. Ding Y, Jiang Z, Saha K, et al. Gold nanoparticles for nucleic acid delivery. Mol Ther. 2014;22:1075-1083.

27. Cheang TY, Tang B, Xu AW, et al. Promising plasmid DNA vector based on APTES modified silica nanoparticles. Int J Nanomedicine. 2012;7:1061-1067.

28. Wen S, Zheng F, Shen M, Shi X. Surface modification and PEGylation of branched polyethyleneimine for improved biocompatibility. J Appl Polym Sci. 2013;128:3807-3813.

29. Durocher $Y$, Perret S, Kamen A. High-level and high-throughput recombinant protein production by transient transfection of suspensiongrowing human 293-EBNA1 cells. Nucleic Acids Res. 2002;30:E9

30. Kreiss $\mathrm{P}$, Cameron B, Rangara R, et al. Plasmid DNA size does not affect the physicochemical properties of lipoplexes but modulates gene transfer efficiency. Nucleic Acids Res. 1999;27:3792-3798.

31. Barese CN, Krouse AE, Metzger ME, et al. Thymidine kinase suicide gene-mediated ganciclovir ablation of autologous gene-modified rhesus hematopoiesis. Mol Ther. 2012;20:1932-1943.

32. Benjaminsen RV, Mattebjerg MA, Henriksen JR, Moghimi SM, Andresen TL. The possible 'proton sponge' effect of polyethylenimine (PEI) does not include change in lysosomal $\mathrm{pH}$. Mol Ther. 2013;21:149-157.

33. Moghimi SM, Symonds P, Murray JC, Hunter AC, Debska G, Szewczyk A. A two-stage poly(ethylenimine)-mediated cytotoxicity: Implications for gene transfer/therapy. Mol Ther. 2005;11:990-995.

34. Boeckle S, von Gersdorff K, van der Piepen S, Culmsee C, Wagner E, Ogris M. Purification of polyethylenimine polyplexes highlights the role of free polycations in gene transfer. J Gene Med. 2004;6:1102-1111.

35. Oh Y-K, Suh D, Kim JM, Choi H-G, Shin K, Ko JJ. Polyethyleniminemediated cellular uptake, nucleus trafficking and expression of cytokine plasmid DNA. Gene Ther. 2002;9:1627-1632.

36. Godbey WT, Barry MA, Saggau P, Wu KK, Mikos AG. Poly (ethylenimine)-mediated transfection: A new paradigm for gene delivery. J Biomed Mater Res. 2000;51:321-328.

37. Huh SH, Do HJ, Lim HY, et al. Optimization of $25 \mathrm{kDa}$ linear polyethylenimine for efficient gene delivery. Biologicals. 2007;35:165-171.

38. Lukacs GL, Haggie P, Seksek O, Lechardeur D, Freedman N, Verkman AS. Size-dependent DNA mobility in cytoplasm and nucleus. J Biol Chem. 2000;275:1625-1629.

39. Campeau P, Chapdelaine P, Massie B, Tremblay JP. Transfection of large plasmids in primary human myoblasts. Gene Ther. 2001;8:1387-1394.

40. Zhang Y, Hu L, Yu D, Gao C. Influence of silica particle internalization on adhesion and migration of human dermal fibroblasts. Biomaterials. 2010;31:8465-8474. 
41. Stern ST, Adiseshaiah PP, Crist RM. Autophagy and lysosomal dysfunction as emerging mechanisms of nanomaterial toxicity. Part Fibre Toxicol. 2012;9:20

42. Sokolov K, Follen M, Aaron J, et al. Real-time vital optical imaging of precancer using anti-epidermal growth factor receptor antibodies conjugated to gold nanoparticles. Cancer Res. 2003;63:1999-2004.

43. Kattumuri V, Katti K, Bhaskaran S, et al. Gum arabic as a phytochemical construct for the stabilization of gold nanoparticles: In vivo pharmacokinetics and X-ray-contrast-imaging studies. Small. 2007;3:333-341.

44. Zhang Q, Iwakuma N, Sharma P, et al. Gold nanoparticles as a contrast agent for in vivo tumor imaging with photoacoustic tomography. Nanotechnology. 2009;20:395102

\section{SUPPORTING INFORMATION}

Additional Supporting Information may be found online in the supporting information tab for this article.

How to cite this article: Encabo-Berzosa MM, Sancho-Albero M, Sebastian V, et al. Polymer functionalized gold nanoparticles as nonviral gene delivery reagents. J Gene Med. 2017;19: e2964. https://doi.org/10.1002/jgm.2964 